\title{
Toll-like receptor 9 dependent activation of MAPK and NF-KB is required for the CpG ODN-induced matrix metalloproteinase-9 expression
}

\author{
Eun-Jung $\operatorname{Lim}^{1,3 *}$, Sun-Hye Lee $^{1,3 *}$, \\ Jin-Gu Lee ${ }^{1,3}$, Jae-Ryong Kim ${ }^{1,3}$, \\ Sung-Su Yun ${ }^{2}$, Suk-Hwan Baek ${ }^{1,3}$ and \\ ChuHee Lee Le, $^{1,3,4}$ \\ ${ }^{1}$ Department of Biochemistry and Molecular Biology \\ ${ }^{2}$ Department of Surgery \\ ${ }^{3}$ Aging-Associated Vascular Disease Research Center \\ College of Medicine, Yeungnam University \\ Daegu 705-717, Korea \\ ${ }^{4}$ Corresponding author: Tel, 82-53-620-4522; \\ Fax, 82-53-654-6651; E-mail, chlee2@ynu.ac.kr \\ ${ }^{*}$ These authors contributed equally to this work.
}

Accepted 11 December 2006

Abbreviations: CpG ODN, CpG oligodeoxynucleotide; MMP, matrix metalloproteinase; TLR9, toll-like receptor 9

\begin{abstract}
Unmethylated CpG oligodeoxynucleotides (CpG ODNs) activate immune cells to produce immune mediators. This study demonstrates that in murine macrophage RAW 264.7 cells, CpG ODN-mediated matrix metalloproteinase-9 (MMP-9) expression is regulated at transcriptional level and requires de novo protein synthesis. Inhibition of ERK and p38 MAPK, but not JNK, results in significant decrease of CpG ODN-induced MMP-9 expression. We found that endosomal maturation inhibitors, chloroquine and bafilomycin A, block CpG ODN-induced ERK and p38 MAPK activation and the subsequent MMP-9 expression. We also observed that CpG ODN induces $\mathrm{NF}-\mathrm{kB}$ activation and NF- $\mathrm{KB}$ is a downstream target of p38 MAPK. Taken together, our data demonstrate that CpG ODN triggers MMP-9 expression via TLR-9 dependent ERK and p38 MAPK activation followed by NF- $\kappa B$ activation.
\end{abstract}

Keywords: CpG-oligonucleotide; extracellular signal-regulated MAP kinases; matrix metalloproteinase 9; NF-kappa B; p38 mitogen-activated protein kinases; Toll-like receptor 9

\section{Introduction}

Pathogen-derived structures activating the innate immune system include: cell wall products such as LPS and peptidoglycan, nucleic acids such as dsRNA, viral RNAs, and bacterial DNA (Janeway and Medzhitov, 2002). Bacterial DNA has been shown to directly target NK cells, B cells, macrophages, and dendritic cells and plays an important role in the innate immune system (Yamamoto et al., 1992; Krieg et al., 1995; Stacey et al., 1996; Sparwasser et al., 1998). Immunostimulatory activity of bacterial DNA depends on unmethylated CpG dinucleotides in particular base contexts ("CpG motif") (Klinman et al., 1996; Krieg, 2002). Synthetic oligodeoxynucleotides containing CpG motifs (CpG oligodeoxynucleotides, CpG ODNs) mimic bacterial DNA immunostimulatory activity (Yi et al., 1998).

CpG ODNs are recognized by a Toll-like receptor (TLR) 9 (Hemmi et al., 2000), which is expressed in the endoplasmic reticulum and transposes to DNAcontaining endosomes (Latz et al., 2004). Cellular recognition of bacterial DNA occurs after nonsequence-specific receptor-mediated uptake and endosomal acidification (Hacker et al., 1998, Macfarlane and Manzel, 1998). The nature of the receptor(s) mediating the uptake of exogenous DNA remains uncertain. Cytoplasmic domains allow TLRs to use signaling molecules used by the interleukin 1 receptors (IL-1Rs): these include MyD88, IL-1R-associated protein kinase and tumor necrosis factor receptor-activated factor 6 . Signal transduction pathways activated by TLRs induce the transcription of a series of cytokine/chemokine genes that are involved in the initiation or regulation of the inflammatory response. However, the recent progress in our understanding of TLR functions is accumulating that the signaling pathways associated with each TLR are not identical and may result in different biological responses.

Matrix metalloproteinase (MMP) is capable of basement membrane degradation in vivo. MMP-9 expression normally only occurs in trophoblasts, osteoclasts, and leukocytes and their precursors and is involved in migration and infiltration of immune and inflammatory cells (Borregaard et al., 1995; Harvey et al., 1995; Witty et al., 1996). Transcription of MMP-9 can be readily induced by a multitude of 
agents including growth factors, cytokines, adhesion molecules, and other factors which induce cell shape alteration (Dong et al., 2001; Martin et al., 2001). Recently, we reported that CpG ODN is an inducer of MMP-9 through TLR-9 and Akt pathway (Lim et al., 2006).

MAPK cascades are evolutionarily well conserved in all eukaryotic cells. These kinases play an important role in linking a variety of extracellular signals to cellular events such as growth, differentiation, apoptosis and inflammatory response (Chang and Karin, 2001). The activation of MAPK cascades, which in turn activates $N F-\kappa B$, has been well characterized in cells of the mammalian immune system (Hacker et al., 2002). NF-кB plays a central role in inflammation by regulating expression of genes that encode pro- inflammatory cytokines, chemokines and inducible enzymes such as iNOS in mammalian immune cells (Hanada and Yoshimura, 2002). Induction of cell signaling pathways including MAPK and $N F-\kappa B$ in response to $C p G$ ODN has been reported in various cells. For example, CpG ODNstimulated plasmacytoid dendritic cells (PDCs), NK cells, and B cells produce Th1-like proinflammatory cytokines, interferons, and chemokines (Krieg, 2002).

In this study, we demonstrated that CpG ODN elicits MMP-9 release from murine macrophage RAW 264.7 cells. MMP-9 expression and its biologic activity were blocked by inhibitors of TLR-9, ERK, p38 MAPK, and NF- $\mathrm{B}$, indicating that TLR-9 dependent ERK and p38 MAPK activation and the

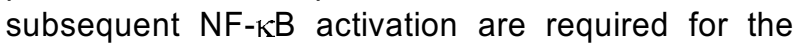
CpG ODN-induced MMP-9 expression.

\section{Materials and Methods}

\section{Reagents and antibodies}

Oligodeoxynucleotide (ODN) 1688, 5'-TCCATGACGTTCCTGATGCT-3' and ODN1722, 5'-TCCATGAGCTTCCTGATGCT-3' were synthesized by Xenotech (Daejoun, Korea), and endotoxin content of these oligonucleotides was measured using a chromogenic limulus amoebocyte lysate kit (BioWhittaker, Walkersville, MD). MAPK inhibitors, U0126 and SB203580, and NF- $\kappa B$ inhibitor, SN-50, and endosomal maturation inhibitor, bafilomycin $A$, were obtained from Calbiochem (San Diego, CA) and chloroquine was purchased from Sigma-Aldrich Co. (St. Louis, MO). For Western blot analysis, we used Abs against ERK1/2, p38 MAPK, NF- $\mathrm{B}$ and $l_{\kappa} \mathrm{B} \alpha$ (Cell Signaling Technology, Beverly, MA), and MMP9 (Santa-Cruz Biotechnology, Santa-Cruz, CA). Peroxidase-conjugated anti-rabbit lgG, anti-goat lgG, or anti-mouse IgG (Santa-Cruz Biotechnology, SantaCruz, CA) were used as secondary antibodies.

\section{Cell culture}

RAW 264.7 cells were obtained from the American Type Culture Collection and were cultured in RPMI 1640 (Gibco BRL, Gaithersburg, MD) containing $10 \%$ FBS, $2 \mathrm{mM}$ L-glutamine, $10 \mathrm{U} / \mathrm{ml}$ penicillin, and $10 \mu \mathrm{g} / \mathrm{ml}$ streptomycin at $37^{\circ} \mathrm{C}$ in $5 \% \mathrm{CO}_{2}$ in a water-saturated atmosphere.

\section{Gelatin zymography}

MMP-9 activity was evaluated using gelatin zymography employing $8 \%$ SDS-polyacrylamide gel containing $0.1 \%$ gelatin as a substrate. After electrophoresis, gels were washed three times with $2.5 \%$ Triton X-100 solution and then incubated overnight at $37^{\circ} \mathrm{C}$ in $0.2 \%$ Brij 35, $5 \mathrm{mM} \mathrm{CaCl}_{2}, 1 \mathrm{mM} \mathrm{NaCl}$, and 50 $\mathrm{mM}$ Tris, at $\mathrm{pH} 7.4$, in a closed container. Gels were then stained for 30 min with $0.25 \%$ Coomassie R-250 in $10 \%$ acetic acid and $45 \%$ methanol and then destained for 30 min using an aqueous mix of $20 \%$ acetic acid, $20 \%$ methanol, and $17 \%$ ethanol. Areas of MMP-9 activity appeared as clear bands.

\section{Western blot analysis}

RAW 264.7 cells were stimulated with $1 \mu \mathrm{M}$ ODN 1688 , washed twice in cold PBS, and lysed on ice using lysis solution ( $1 \%$ Triton $X-100,50 \mathrm{mM}$ Tris (pH 8.0), $150 \mathrm{mM} \mathrm{NaCl}, 1 \mathrm{mM}$ PMSF, $1 \mathrm{mM} \mathrm{Na}_{3} \mathrm{VO}_{4}$, and protease inhibitor cocktail). Protein concentrations were determined using Bio-Rad protein assays. Briefly, proteins from cell lysates $(50 \mu \mathrm{g})$ were boiled at $95^{\circ} \mathrm{C}$ in Laemmli SDS loading buffer, separated on $8 \%$ SDS-PAGE, and electrotransferred to nitrocellulose membranes. Membranes were blocked for $30 \mathrm{~min}$ at room temperature in Tris buffered saline- $0.05 \%$ Tween-20 (TTBS) containing 5\% non-fat dry milk, and then incubated with TTBS containing a primary antibody for $4 \mathrm{~h}$ at room temperature. After $5 \times 10 \mathrm{~min}$ washes in TTBS, membranes were incubated with peroxidase-conjugated secondary antibody for $1 \mathrm{~h}$. Following 5 additional 10 min washes with TTBS, protein bands of interest were visualized using an enhanced chemiluminescence detection system (Amersham).

\section{Establishment of stable cell line containing NF-KB luciferase reporter construct}

A promoter-reporter construct containing 8 copies of the NF-kB element was transfected into RAW 264.7 cells using Lipofectamine 2000. After transfection, cells were incubated in complete media for $24 \mathrm{~h}$ at $37^{\circ} \mathrm{C}$, and transfectants were selected under 400 $\mu \mathrm{g} / \mathrm{ml}$ G418. Established RAW/NF- $\kappa \mathrm{B}$ cells were stimulated with $\mathrm{CpG} O \mathrm{ODN}$ for $6 \mathrm{~h}$ at $37^{\circ} \mathrm{C}$. In some experiments, cells were preincubated with a specific 
inhibitor for $1 \mathrm{~h}$ at $37^{\circ} \mathrm{C}$ prior to $\mathrm{CpG}$ ODN stimulation. Cell lysates were assayed for luciferase activity using a luminometer (Promega) according to the manufacturer's instructions.

\section{Results}

\section{CpG ODN-mediated activation of ERK1/2 and p38 MAPK is required for the MMP-9 induction}

Previously, we reported CpG ODN-induced MMP-9 expression. RAW 264.7 murine macrophage cells were stimulated with ODN1688 or ODN1720, which has the same sequence as ODN1688 with a GpC dinucleotide replacing the $\mathrm{CpG}$ motif as a negative control. Conditioned media were collected and examined for a MMP-9 expression using gelatin zymography and western blot analysis. While ODN1720 failed to induce MMP-9, dose and time-dependent MMP-9 expression was observed and detected as early as $6 \mathrm{~h}$ post CpG ODN stimulation and reached a maximum level up to $24 \mathrm{~h}$ later. We further observed that $\mathrm{CpG}$ ODN induces transcriptional up-regulation and de novo protein synthesis of MMP-9 (Lim et al., 2006).
A number of studies showed that activation of MAPK is essential for MMP-9 expression in various cell types. We examined CpG ODN-induced activation of MAPK and its involvement in MMP-9 expression. We tested the effect of MAPK inhibitors on CpG ODN-mediated MMP-9 induction. Prior to CpG ODN treatment, RAW 264.7 cells were pretreated with U0126 and SB203580, which are ERK, p38 MAPK inhibitors, respectively. CpG ODN-induced MMP-9 release into culture media was determined by gelatin zymograph and Western blot analysis. As shown in Figure 1A, inhibition of either ERK or p38 MAPK resulted in a significant decrease in MMP-9 expression from CpG ODN-stimulated cells. While SP600125, JNK inhibitor, had no effect on CpG ODN-mediated MMP-9 expression (data not shown), indicating that activation of ERK and p38 MAPK, but not JNK, is required for the CpG ODN-induced MMP-9 expression.

Since our previous data showed that MMP-9 expression by $\mathrm{CpG}$ ODN precedes TNF- $\alpha$ induction, we next examined whether inhibition of ERK or p38 MAPK has an effect on the CpG ODN-induced TNF- $\alpha$ production which leads to MMP-9 expression. As seen in Figure $1 \mathrm{~B}$, TNF- $\alpha$ production in response to $\mathrm{CpG}$ ODN was significantly reduced in the pre-
A
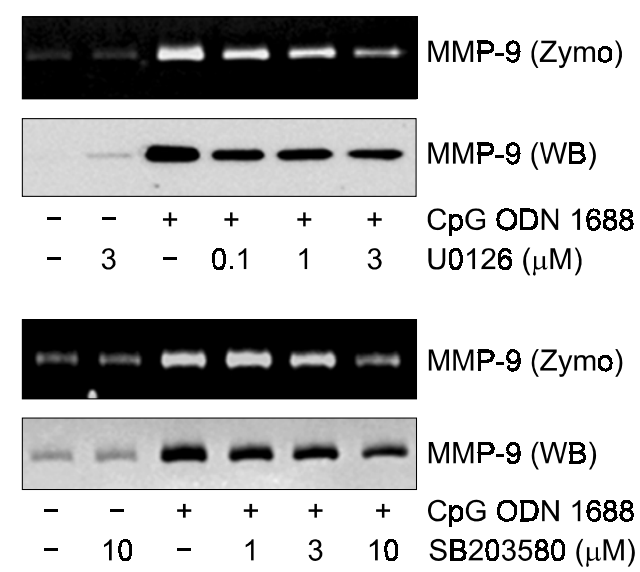

B

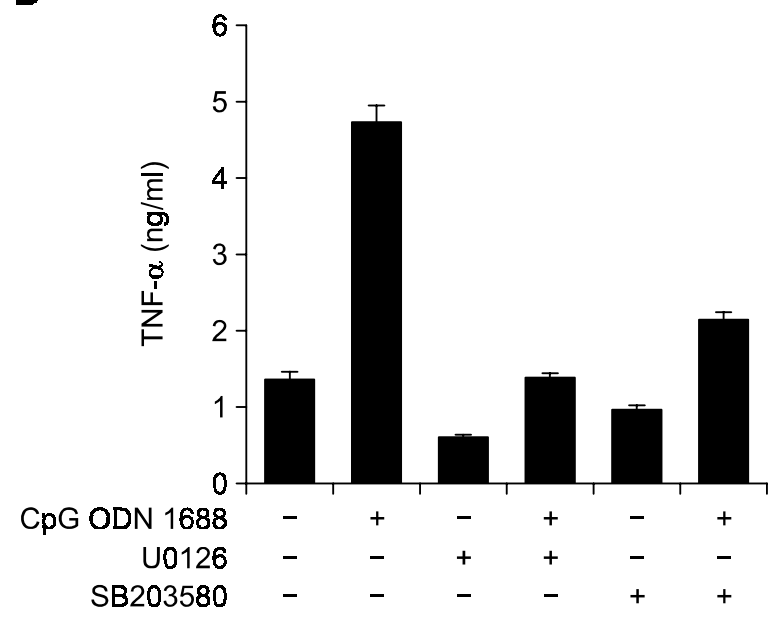

C

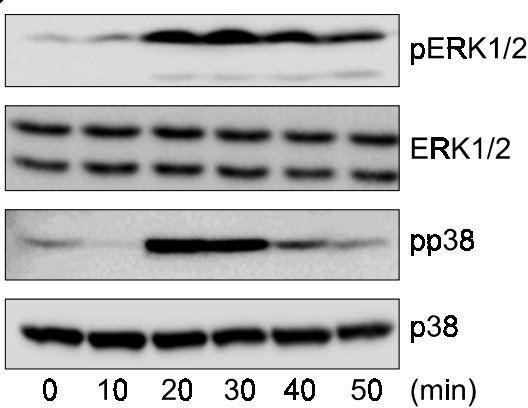

Figure 1. CpG ODN stimulates ERK1/2 and p38 MAPK, but not JNK, activation which is required for the MMP-9 induction. (A) RAW 264.7 cells were pretreated with the indicated concentrations of U0126 or SB203580 for $1 \mathrm{~h}$ followed by stimulation with $1 \mu \mathrm{M}$ ODN1688 for $24 \mathrm{~h}$. The conditioned media were collected and analyzed for MMP activity by zymography and Western blot. (B) RAW 264.7 cells were pretreated with $1 \mu \mathrm{M}$ U0126 or $10 \mu \mathrm{M}$ SB203580 for $1 \mathrm{~h}$ followed by stimulation with $1 \mu \mathrm{M}$ ODN1688 for $6 \mathrm{~h}$. The level of TNF- $\alpha$ in conditioned media was measured by ELISA. (C) RAW 264.7 cells were stimulated with $1 \mu \mathrm{M}$ ODN1688 as indicated. Whole cell lysates were prepared and analyzed by Western blot analysis. Equal amounts of proteins were loaded and immunoblot was performed with phosphospecific antibodies of ERK and p38 MAPK. Immunoblot with anti-ERK and p38 MAPK antibodies were used as the loading control. Results are from three independent experiments. 
sence of either U0126 or SB203580, suggesting that both ERK and p38 MAPK activation are required for the CpG ODN-mediated TNF- $\alpha$ production, which influences the subsequent MMP-9 expression.

To confirm the involvement of ERK and p38 MAPK activation in CpG ODN induced MMP-9 expression, phosphorylation of these kinases by CpG ODN was observed. ERK phosphorylation was detected at 20 min after CpG ODN stimulation and sustained up to $50 \mathrm{~min}$. It seems that p38 MAPK phosphorylation is a bit temporal, since its phosphrylation was found at 20-30 min and declined to almost basal level by 40 min (Figure 1C).

\section{CpG ODN-mediated activation of ERK and p38 MAPK is TLR-9 dependent}

Internalization and endosomal maturation have been shown to be required for CpG DNA to activate TLR9 signaling in immune cells (Krieg, 1999; AhmadNejad et al., 2002). We examined if TLR-9 is responsible for the CpG ODN mediated ERK and p38 MAPK activation. Both chloroquine and bafilomycin
A which effectively block endosomal maturation, significantly inhibited the phosphorylation of ERK and p38 MAPK by CpG ODN (Figure 2A), which resulted in the suppression of MMP-9 expression (Figure 2B). These results imply that CpG ODN elicits TLR-9 dependent activation of ERK and p38 MAPK and the subsequent MMP-9 expression.

\section{NF- $\mathrm{BB}$ activation is involved in CpG ODN-mediated MMP-9 induction}

Since NF-KB is one of the well known transcription factors which regulate MMP-9 expression, we addressed involvement of NF-kB activation in $\mathrm{CpG}$ ODN-mediated MMP-9 induction. RAW 264.7 cells were treated with $1 \mu \mathrm{M}$ ODN1688 for 10 to $60 \mathrm{~min}$ and whole cell lysates were prepared from those cells. $I_{\kappa} B \alpha$ degradation was determined by Western blot analysis using a specific antibody against the $I_{\kappa} \mathrm{B} \alpha$ subunit. The level of $I_{\kappa} \mathrm{B} \alpha$ was decreased at 20-30 min after stimulation and then recovered to baseline status 40 min later (Figure $3 \mathrm{~A}$ ).

Next, we transfected NF-kB-luciferase reporter
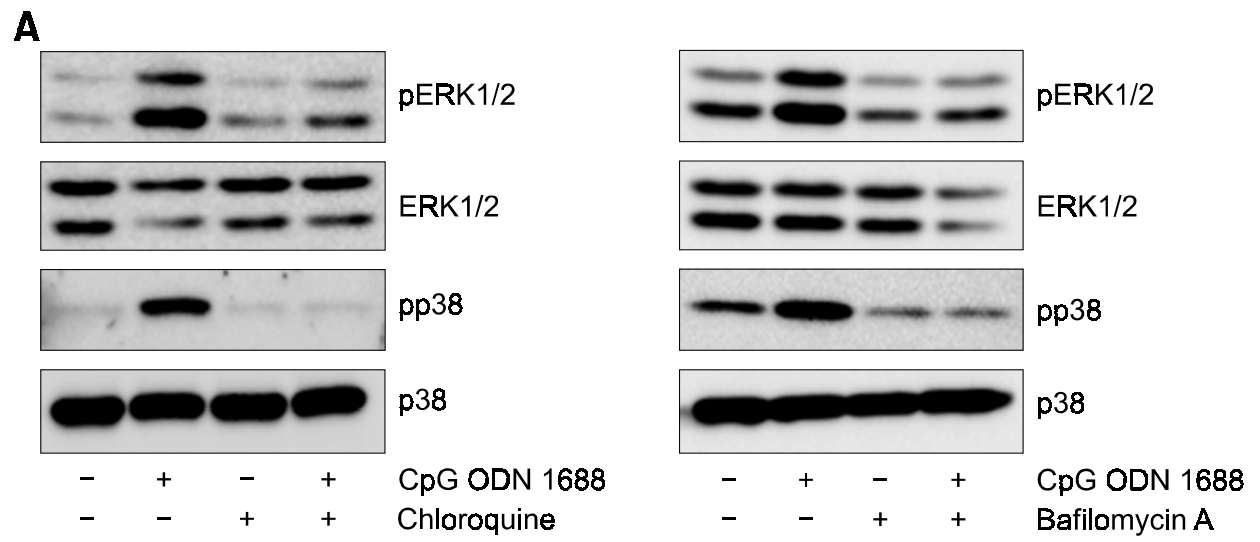

B

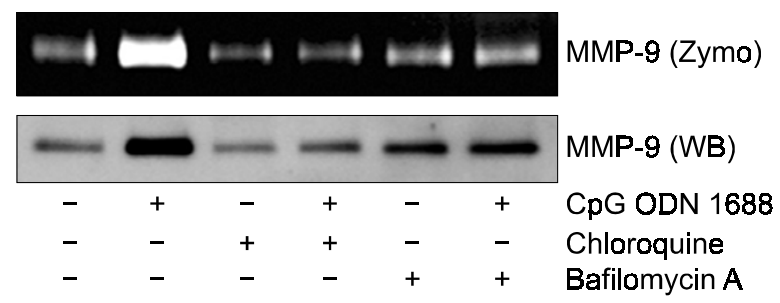

Figure 2. TLR9 inhibitors block CpG ODN induced ERK and p38 MAPK activation and MMP-9 expression. (A) RAW 264.7 cells were pretreated with $3 \mu \mathrm{M}$ chloroquine or $10 \mu \mathrm{M}$ bafilomycin $\mathrm{A}$ for $1 \mathrm{~h}$ followed by stimulation with $1 \mu \mathrm{M}$ ODN1688 for $20 \mathrm{~min}$. Cells were lysed and analyzed by Western blot analysis using phosphospecific antibodies of ERK and p38 MAPK. (B) RAW 264.7 cells were pretreated with $3 \mu \mathrm{M}$ chloroquine or $10 \mu \mathrm{M}$ bafilomycin A for $1 \mathrm{~h}$ followed by stimulation with $1 \mu \mathrm{M}$ ODN1688 for $24 \mathrm{~h}$. The conditioned media were collected and analyzed for MMP activity by zymography and Western blot using MMP-9 antibody. Results are from three independent experiments. 
A

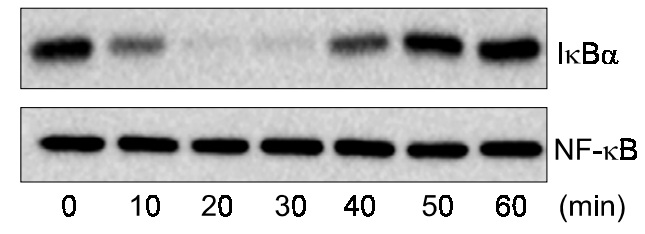

C
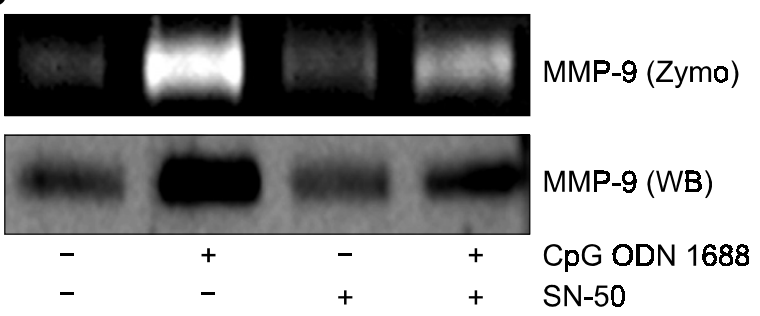

B

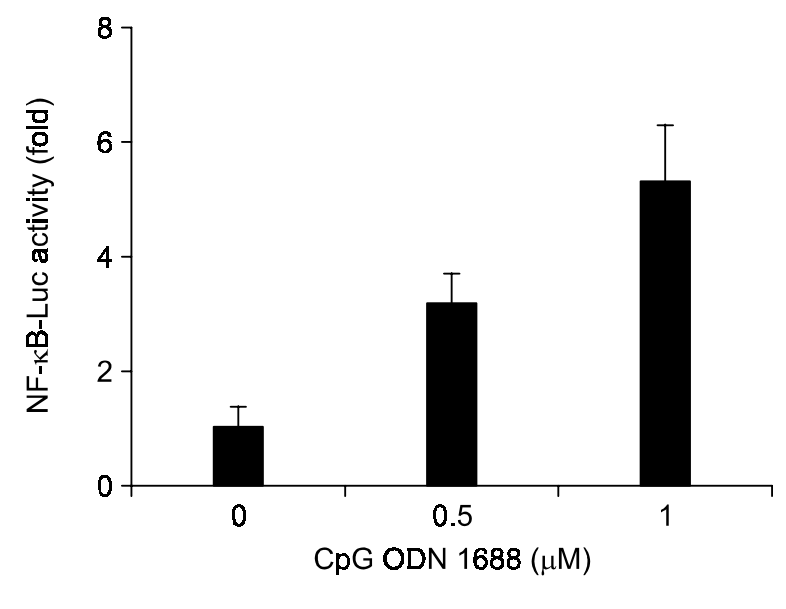

Figure 3. $\mathrm{CpG}$ ODN induces NF-kB activation and NF-kB inhibitor blocks MMP-9 induction. (A) RAW 264.7 cells were stimulated with $1 \mu \mathrm{M}$ ODN1688 as indicated. Cells were lysed and analyzed by Western blot analysis using $I_{\kappa} B \alpha$ antibody. (B) RAW 264.7 cells expressing NF- $\mathrm{K} B$ luciferase reporter construct were treated with the indicated concentrations of ODN1688 for $6 \mathrm{~h}$. Whole cell lysate was prepared and subjected to luciferase assay. (C) Cells were pretreated with the indicated concentrations of IKB kinase inhibitor peptide followed by stimulation with $1 \mu \mathrm{M}$ ODN1688 for 24 $\mathrm{h}$. The conditioned media were collected and analyzed for MMP activity by zymography and Western blot. The data shown are representative of three independent experiments.

construct, which contains 8 consecutive NF-kB binding sites in the upstream of the luciferase gene, into RAW 264.7 cells to establish RAW 264.7/NF-kB. This allowed us to measure NF-KB activation as a function of luciferase activity. RAW 264.7/NF-кB cells were treated with different concentrations of ODN1688 $(0,0.5,1 \mu \mathrm{M})$ for $6 \mathrm{~h}$ and then luciferase activity in whole cell lysates were measured. As shown in Figure 3B, 3.7 to 5.5 fold-increased luciferase activities were observed after CpG ODN treatment, suggesting NF- $\kappa$ B activation by CpG ODN.

To further confirm $\mathrm{CpG}$ ODN-mediated NF-кB activation, the effect of SN-50, NF-kB inhibitor, on MMP-9 induction was examined. RAW 264.7 cells were stimulated with $1 \mu \mathrm{M}$ ODN1688 for $24 \mathrm{~h}$ in the absence or presence of $10 \mu \mathrm{g} / \mathrm{ml} \mathrm{SN}-50$. Gelatin zymography and Western blot analysis were performed with conditioned media. We found SN-50 blocked MMP-9 expression significantly, indicating that NF- $\mathrm{B}$ activation is required for the CpG ODNinduced MMP-9 expression (Figure $3 \mathrm{C}$ ).

\section{NF-kB is the downstream target of p38 MAPK, not ERK1/2, in the CpG ODN-stimulated signaling pathway}

Since both ERK and p38 MAPK activation and NF$\kappa B$ activity are required for the $C p G$ ODN-induced MMP-9 expression, we addressed the possible link between MAPK activation and NF- $\mathrm{KB}$ activity. As illustrated in Figure 4A, pretreatment of SB203580 prior to $\mathrm{CpG}$ ODN stimulation abrogated $\mathrm{I}_{\kappa} \mathrm{B} \alpha$ degradation, while U0126 failed to block ODN-induced $I_{\kappa} B \alpha$ degradation. We also found that NF-kB dependent luciferase activity in RAW 264.7/ NF-kB cells after ODN stimulation was suppressed in the presence of SB203580, but not U0126 (Figure 4B). These results indicate that NF-KB is the downstream target of p38 MAPK in the CpG ODN- mediated signal transduction, but not involved in ERK1/2 pathway.

\section{Discussion}

In the present study, we extended our previous observations of CpG ODN-induced MMP-9 expression in murine macrophage RAW 264.7 cells. We further found that the CpG ODN elicits TLR-9 dependent ERK and p38 MAPK activation and the subsequent NF-KB activation to produce MMP-9.

Investigators have reported that ERK1/2, JNK, and p38 MAPK are all involved in the induction of MMPs (Werle et al., 2002; Spallarossa et al., 2005). For example, Werles et al. (2002) showed that monocyte chemoattractant protein (MCP)-1 can lead to direct activation of MAPK together with induction of MMP2 in vascular endothelial cells. Our work showed that inhibition of ERK and p38 MAPK using U0126 and SB203580, respectively, prevents CpG ODN-induced MMP-9 expression. However, JNK inhibitor SP600125 failed to inhibit MMP-9 release after CpG ODN treatment, suggesting that activation of ERK and p38 
A

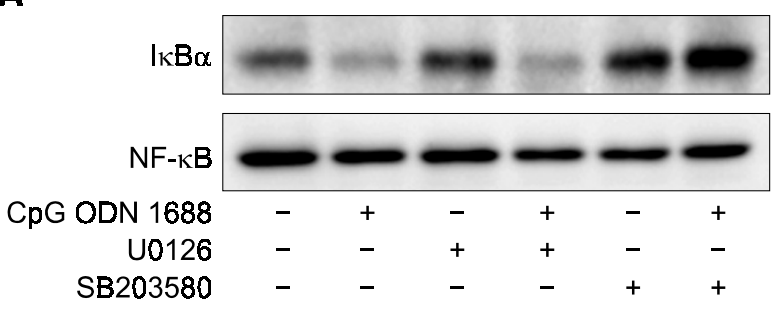

B

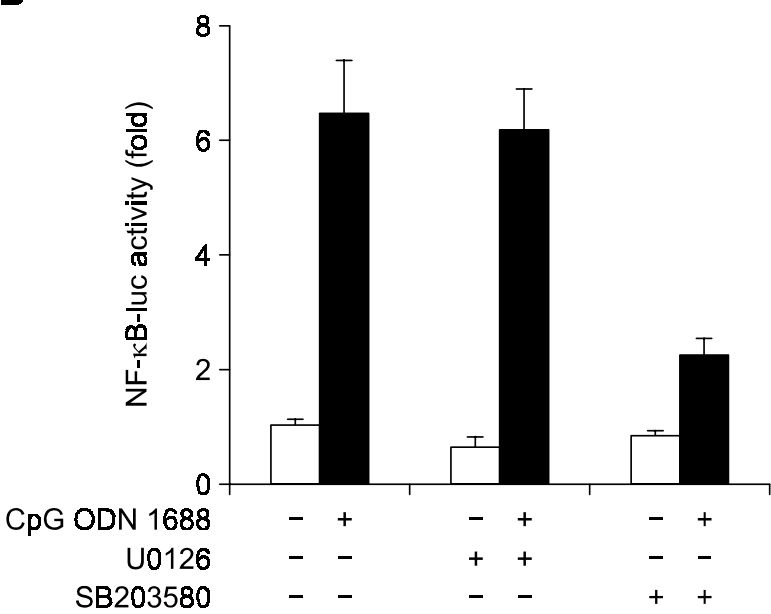

Figure 4. Inhibition of p38 MAPK, but not ERK1/2, prevents CpG ODN-induced NF-KB activation. (A) RAW 264.7 cells were pretreated with the indicated concentrations of $3 \mu \mathrm{M} \cup 0126$, or $10 \mu \mathrm{M}$ SB203580 for $1 \mathrm{~h}$ followed by stimulation with $1 \mu \mathrm{M}$ ODN1688 for $20 \mathrm{~min}$. Cells were lysed and analyzed by Western blot analysis using $I_{\kappa} B \alpha$ antibody. (B) RAW 264.7 cells expressing NF-kB luciferase reporter construct were treated with the $3 \mu \mathrm{M} U 0126$ or $10 \mu \mathrm{M}$ SB203580 for $1 \mathrm{~h}$ followed by ODN1688 for $6 \mathrm{~h}$. Whole cell lysates were prepared and subjected to luciferase assay. The data shown are representative of three independent experiments.

MAPK, but not JNK, is critical for mediating CpG-induced production of MMP-9 from macrophage cells.

CpG ODNs have been shown to activate MAPK. Hacker et al. (1998) also reported that CpG ODN activates the MAPK kinase-ERK pathway in RAW 264.7 macrophage cell line, which plays an important role in IL-12 production from these cells. In contrast to RAW 264.7, they reported that CpG ODN activates JNK and p38 MAPK in bone marrow-derived dendritic cells. The role of JNK2 has been investigated in Th1 differentiation, and IL-12 fails to induce differentiation of JNK2-deficient $\mathrm{CD}^{+}{ }^{+} \mathrm{T}$ cells into effector Th1 cells (Dong et al., 1998, 2000) and cytokine production from $B$ cell lines and monocytic cell lines (Yi et al., 1996, 1998). These observations suggest that ERK, JNK, and p38 MAPK-signaling pathways play an important role in the induction of immune responses by $\mathrm{CpG}$ ODN. In our present study, we also demonstrated that CpG phosphorylates ERK and p38 MAPK in RAW 264.7 cells.

The NF-kB responsive element is present in the promoter region of MMP-9. It has recently reported that $\mathrm{CpG}$ ODN regulates NF-kB-mediated-MMP-9 activation and controls cell migration (Rhee et al., 2007). We also observed NF- $\mathrm{kB}$ activation by $\mathrm{CpG}$ ODN. As shown in Figure $3 \mathrm{~A}$ and $3 \mathrm{~B}, \mathrm{CpG}$ ODN elicits $I_{\kappa} B \alpha$ degradation and increases luciferase activity in RAW 264.7 cells containing NF-kB-luciferase reporter construct. We further found that NF-kB inhibitor, SN-50, blocked MMP-9 expression, indicating that NF- $\mathrm{KB}$ activation is required for the CpG ODN-induced MMP-9 expression.

MAPK, either through direct or indirect interaction with transcription factors such as NF-kB, regulates various biological functions. To address whether MAPK activation is associated with NF-KB activity in CpG ODN-induced MMP-9 expression, RAW 264.7 cells were stimulated with CpG ODN in the absence or presence of U0126 and SB203580. We found that $I_{\kappa} B \alpha$ degradation and NF- $\kappa B$ dependent luciferase activity were suppressed by SB203580 pretreatment, indicating CpG ODN activates p38 MAPK/NF-kB/ MMP-9 pathway in RAW 264.7 cells.

However, ERK activation by CpG ODN dose not seem to lead to NF-KB activation, since ERK inhibitor, U0126, has no effect on $I_{\kappa} B \alpha$ degradation and $\mathrm{NF}-\kappa \mathrm{B}$ dependent luciferase activity in response to CpG ODN. In addition to NF- $\kappa$ B binding site, MMP-9 promoter region contains $A P-1$ bindig site and a recent report showed that ERK/AP-1 signaling pathway is involved in the MMP-9 expression by hepatitis $B$ virus $X$ protein (Chung et al., 2004). Therefore, we speculate that CpG ODN-induced ERK activation might lead to AP-1 activation which is followed by MMP-9 expression.

In summary, we demonstrate a mechanism of the CpG ODN-mediated MMP-9 expression in macrophage cells, which involves TLR9, ERK and p38 MAPK activation, and the subsequent NF-KB dependent transcriptional up-regulation.

\section{Acknowledgement}

This work was supported by the Aging-Associated Vascular Disease Research Center at Yeungnam University of Korea Science and Engineering Foundation (Grant No. R13-2005-005-01003-0 (2006)) and by Korea Research Foundation Grant funded by the Korean Government (MOEHRD, Basic Research Promotion Fund) (R03-2004000-10009-0).

\section{References}

Ahmad-Nejad P, Hacker H, Rutz M, Bauer S, Vabulas RM, 
Wagner H. Bacterial CpG-DNA and lipopolysaccharides activate Toll-like receptors at distinct cellular compartments. Eur J Immunol 2002;32:1958-68

Akira S, Takeda K, Kaisho T. Toll-like receptors: critical proteins linking innate and acquired immunity. Nat Immunol 2001;2:675-80

Borregaard N, Sehested M, Nielsen BS, Sengelov H, Kjeldsen $\mathrm{L}$. Biosynthesis of granule proteins in normal human bone marrow cells. Gelatinase is a marker of terminal neutrophil differentiation. Blood 1995;85:812-7

Chang L, Karin M. Mammalian MAP kinase signalling cascades. Nature 2001;410:37-40

Chung TW, Lee YC, Kim CH. Hepatitis B viral HBx induces matrix metalloproteinase-9 gene expression through activation of ERKs and PI-3K/AKT pathways: involvement of invasive potential. FASEB J 2004;18:1123-35

Dong C, Yang DD, Wysk M, Whitmarsh AJ, Davis RJ, Flavell RA. Defective T cell differentiation in the absence of Jnk1. Science 1998;282:2092-5

Dong C, Yang DD, Tournier C, Whitmarsh AJ, Xu J, Davis RJ, Flavell RA. JNK is required for effector T-cell function but not for T-cell activation. Nature 2000;405:91-4

Dong Z, Nemeth JA, Cher ML, Palmer KC, Bright RC, Fridman $R$. Differential regulation of matrix metalloproteinase-9, tissue inhibitor of metalloproteinase-1 (TIMP-1) and TIMP-2 expression in co-cultures of prostate cancer and stromal cells. Int J Cancer 2001;93:507-15

Hacker G, Redecke V, Hacker H. Activation of the immune system by bacterial CpG-DNA. Immunology 2002;105:24551

Hacker $H$, Mischak $H$, Miethke T, Liptay S, Schmid R, Sparwasser T, Heeg K, Lipford GB, Wagner H. CpG-DNAspecific activation of antigen-presenting cells requires stress kinase activity and is preceded by non-specific endocytosis and endosomal maturation. Embo J 1998;17:6230-40

Hanada T, Yoshimura A. Regulation of cytokine signaling and inflammation. Cytokine Growth Factor Rev 2002;13:413-21

Harvey MB, Leco KJ, Arcellana-Panlilio MY, Zhang X, Edwards DR, Schultz GA. Proteinase expression in early mouse embryos is regulated by leukaemia inhibitory factor and epidermal growth factor. Development 1995;121:1005-14

Hemmi H, Takeuchi O, Kawai T, Kaisho T, Sato S, Sanjo H, Matsumoto M, Hoshino K, Wagner H, Takeda K, Akira S. A Toll-like receptor recognizes bacterial DNA. Nature 2000;408: $740-5$

Janeway CA Jr, Medzhitov R. Innate immune recognition. Annu Rev Immunol 2002;20:197-216

Klinman DM, Yi AK, Beaucage SL, Conover J, Krieg AM. CpG motifs present in bacteria DNA rapidly induce lymphocytes to secrete interleukin 6 , interleukin 12, and interferon gamma. Proc Natl Acad Sci USA 1996;93:2879-83

Krieg AM, Yi AK, Matson S, Waldschmidt TJ, Bishop GA, Teasdale R, Koretzky GA, Klinman DM. CpG motifs in bacterial DNA trigger direct B-cell activation. Nature 1995;374:546-9

Krieg AM. Direct immunologic activities of CpG DNA and implications for gene therapy. J Gene Med 1999;1:56-63

Krieg AM. CpG motifs in bacterial DNA and their immune effects. Annu Rev Immunol 2002;20:709-60

Latz E, Schoenemeyer A, Visintin A, Fitzgerald KA, Monks BG, Knetter CF, Lien E, Nilsen NJ, Espevik T, Golenbock DT. TLR9 signals after translocating from the ER to CpG DNA in the Iysosome. Nat Immunol 2004;5:190-8

Lim EJ, Lee SH, Lee JG, Chin BR, Bae YS, Kim JR, Lee CH, Baek SH. Activation of toll-like receptor-9 induces matrix metalloproteinase-9 expression through Akt and tumor necrosis factor-alpha signaling. FEBS Lett 2006; 580:4533-8

Macfarlane DE, Manzel L. Antagonism of immunostimulatory CpG-oligodeoxynucleotides by quinacrine, chloroquine, and structurally related compounds. J Immunol 1998;160:1122-31

Martin J, Eynstone L, Davies M, Steadman R. Induction of metalloproteinases by glomerular mesangial cells stimulated by proteins of the extracellular matrix. J Am Soc Nephrol 2001;12:88-96

Rhee JW, Lee KW, Sohn WJ, Lee Y, Jeon OH, Kwon HJ, Kim DS. Regulation of matrix metalloproteinase- 9 gene expression and cell migration by NF-kappaB in response to CpG-oligodeoxynucleotides in RAW 264.7 cells. Mol Immunol 2007;44:1393-400

Spallarossa P, Altieri P, Garibaldi S, Ghigliotti G, Barisione C, Manca V, Fabbi P, Ballestrero A, Brunelli C, Barsotti A. Matrix metalloproteinase-2 and -9 are induced differently by doxorubicin in $\mathrm{H} 9 \mathrm{c} 2$ cells: the role of MAP kinases and $\mathrm{NAD}(\mathrm{P}) \mathrm{H}$ oxidase. Cardiovasc Res 2005;69:736-45

Sparwasser T, Koch ES, Vabulas RM, Heeg K, Lipford GB, Ellwart JW, Wagner $\mathrm{H}$. Bacterial DNA and immunostimulatory CpG oligonucleotides trigger maturation and activation of murine dendritic cells. Eur J Immunol 1998;28:2045-54

Stacey KJ, Sweet MJ, Hume DA. Macrophages ingest and are activated by bacterial DNA. J Immunol 1996;157:2116-22

Werle M, Schmal U, Hanna K, Kreuzer J. MCP-1 induces activation of MAP-kinases ERK, JNK and p38 MAPK in human endothelial cells. Cardiovasc Res 2002;56:284-92

Witty JP, Foster SA, Stricklin GP, Matrisian LM, Stern PH. Parathyroid hormone-induced resorption in fetal rat limb bones is associated with production of the metalloproteinases collagenase and gelatinase B. J Bone Miner Res 1996;11:72-8

Yamamoto S, Yamamoto T, Shimada S, Kuramoto E, Yano O, Kataoka T, Tokunaga T. DNA from bacteria, but not from vertebrates, induces interferons, activates natural killer cells and inhibits tumor growth. Microbiol Immunol 1992;36:983-97

Yi AK, Chace JH, Cowdery JS, Krieg AM. IFN-gamma promotes IL-6 and IgM secretion in response to CpG motifs in bacterial DNA and oligodeoxynucleotides. J Immunol 1996; 156:558-64

Yi AK, Krieg AM. Rapid induction of mitogen-activated protein kinases by immune stimulatory CpG DNA. J Immunol 1998;161:4493-7

Yi AK, Peckham DW, Ashman RF, Krieg AM. CpG DNA rescues $B$ cells from apoptosis by activating NFkappaB and preventing mitochondrial membrane potential disruption via a chloroquine-sensitive pathway. Int Immunol 1999;11:2015-24 